\title{
Research on the Dynamic Compensation Method of the Shock Wave's Evaluation Pressure Sensor
}

Wei Wang ( $\nabla$ wangwei62@nuc.edu.cn )

\section{Research}

Keywords: Dynamic characteristics of pressure sensor, Compensation method, PFQPSO algorithm, Blast shock wave

Posted Date: September 4th, 2020

DOI: https://doi.org/10.21203/rs.3.rs-39388/v2

License: (c) (i) This work is licensed under a Creative Commons Attribution 4.0 International License. Read Full License 
Research on the Dynamic Compensation Method of the Shock Wave's Evaluation Pressure

\title{
Sensor \\ Wei Wang*
}

School of Instrument and Electronics, North University of China, Shanxi, Taiyuan, 030051, P.R. China, wangwei62@nuc.edu.cn

[*Corresponding author: Wei Wang]

\begin{abstract}
Due to the steep and changing fast rising edge of explosion shock wave signal, it asks for good dynamic characteristic of sensor and test system. As far as the development of the sensor level, they are difficult to achieve dynamic characteristic requirement of approximate distortionless transmission, so cause a large dynamic error in the actual test. This paper, aiming at providing theoretical support for technology guarantee and service of the shock wave testing system of national shooting range, conducts a research on the method of dynamic characteristic compensation of pressure sensor facing the power evaluation of the blast shock wave. The research proposes and studies the filter design method of dynamic compensation of pressure sensor based on PFQPSO (the progressive function quantum-behaved particle swarm optimization) algorithm, which belongs to inverse modeling. The dynamic compensation can be realized without knowing the model of sensor, so the extra error caused by dynamic modeling of sensors can be avoided. using 8510 series sensor can be used with lower natural frequency and lower measurement range from Endevco Company, this research has had experiment and modeling on the dynamic characteristics of shock tubes as well as design of dynamic compensation filter. Based on the analysis and confirmation, this study illustrates the possibility and effectiveness of this method.
\end{abstract}

Keywords: Dynamic characteristics of pressure sensor; Compensation method; PFQPSO algorithm; Blast shock wave

\section{Introduction}

Explosive shock wave is an important physical quantity for evaluating the power of ammunition explosion and weapon system damage. The accuracy of its pressure characteristic parameter is a key indicator for evaluating the explosive power of ammunition or weapon system. ${ }^{[1]}$. The pressure signal of blast shock wave is a dynamic signal, shown by a rapid rising process generally in several microseconds and long duration in millisecond or even hundreds of milliseconds, so it is a kind of instantaneous change signal with broadband. The measurement of blast shock wave puts forward a higher requirement for the dynamic performance of test system. If the land zone of amplitude-frequency characteristic of test system cannot cover the frequency spectrum of signal to be tested, a larger error of dynamic performance will occur, resulting the distortion of waveform observed. Thus, the test data requires follow-up processing and correction to obtain better results ${ }^{[2]}$. The dynamic characteristic compensation of sensor is an effective method for correcting the dynamic error. Therefore, carrying out research on shock wave testing technology and sensor dynamic characteristics compensation method, objectively and accurately assessing damage power, has important practical significance for the development of weapon systems and damage theory. ${ }^{[3]}$.

The principle of correcting the dynamic error can be concluded into the studies on the restoration to ideal instrument, the frequency characteristic correction of test instrument, the re-construction of input signal, dynamic error compensation, signal error correction, 
deconvolution method and inverse filter technique ${ }^{[4]}$. Studies abroad mainly start from algorithm, first to realize the inverse filter according to priori knowledge of tested signal and adopt lowpass filtering or smoothing for artificial adjustment. Dr. Nahman, the American famous expert on time domain measurement, makes use of frequency domain correction to propose a best single-parameter deconvolution method to estimate tested signal. Its advantages and disadvantages depend on the algorithm of discrete Fourier transformation, suitable for lowpass test system and sensitive to noise ${ }^{[5]}$; American Riad and Stafford jointly propose a compensation method to obtain deconvolutional stable solution, strongly inhibiting noise, which suits the deconvolution with bandpass signal; Parruck et al. calculate the deconvolution of pulse response data, derive approximate step waveform by the integral of pulse response and study the mean value and variance of tail ${ }^{[6]}$; domestically, there are three basic methods of dynamic characteristic error correction, including frequency domain correction, numerical differentiation and superposition integral. These three methods fail to take the impact of error on the stability of results, which are not suitable for measuring signal ${ }^{[7]}$.

Aiming at the dynamic characteristics compensation of the explosive shock wave sensor, further research on the general form of the frequency domain inverse filtering method based on mathematical inversion, research on the fast recursive pseudo-modeling method, and research on the real-time processing method of dynamic characteristics compensation are the purpose of this paper. In order to provide a theoretical basis for the accuracy of the power evaluation, and to provide technical support for the existing test system and the test system under development.

\section{The Improved method}

Researchers have discovered through a large number of studies and experiments that the process of human learning is similar to the quantum behavior of particles, and has great uncertainty. Therefore, a particle in the quantum space can be used to describe an individual, and a quantum potential energy field model can be constructed through the aggregation of swarm intelligence, and then by referring to the characteristics of human group coordination and autonomy, parameter control strategies can be designed. On this basis, a new swarm intelligence algorithm is proposed-Quantum-behaved PSO (QPSO) algorithm with quantum behavior. The quantum-behaved particle swarm optimization (QPSO) is a new PSO (the particle swarm optimization) algorithm model proposed from the perspective of quantum mechanical theory. It changes PSO algorithm evolution search strategy and has no more need of velocity vector, so that the form of evolution equation is simpler and easier to control. Different from standard PSO system, there is also prematurity in QPSO system. After each iteration of QPSO, the search space of individual particle is all the feasible solution space of problems ${ }^{[8]}$. However, due to the aggregation of particles in bound state, the decline of population diversity is unavoidable. In order to improve the global and local searching ability of quantum-behaved particle swarm, the rate of convergence and computational accuracy, this paper integrates new optimization algorithm on the basis of QPSO algorithm, and proposes PFQPSO based on QPSO of progress function.

In the process of system identification, QPSO algorithm is adopted for global searching. Whereas, the accuracy of identification is lower. Thus, the result searched by QPSO is taken as the input value of progress function. The local optimal solution can searched by learning the progress function to enhance the identification accuracy of system parameter ${ }^{[9]}$.

The sensor system can be expressed with univariate difference equation, shown in Equation 
(1).

$$
Y(t)\left(1+a_{1} z^{-1}+\cdots+a_{n} z^{-n}\right)=X(t)\left(b_{0}+b_{1} z^{-1}+\cdots+b_{m} z^{-m}\right)+e(t)
$$

In Equation (1), $Y(t)$ and $X(t)$ are the observable output value and input value. $e(t)$ is noise.

The progress function $\hat{y}(\mathrm{t})$ algorithm is shown in Equation (2).

$$
\hat{y}=\sum_{i=1}^{a_{n}+b_{n}} \phi_{i}(t) U_{i}(t)
$$

In Equation (2), $\phi_{i}(t)$ is progress factor and $\lambda$ is progress rate.

$$
\begin{aligned}
& \phi_{i}(t+1)=\phi_{i}(t)\left[1+\lambda(\hat{y}-y) X_{i}(t)\right] \\
& U_{i}(t)=\left[\begin{array}{lllll}
U_{1} & \mathrm{~L} & U_{n} & \mathrm{~L} & U_{a_{n}+b_{n}}
\end{array}\right] \\
& =\left[\begin{array}{llllll}
Y(t-1) & \mathrm{L} & Y\left(t-a_{n}\right) & X(t-1) & \mathrm{L} & X\left(t-b_{n}\right)
\end{array}\right] \\
& =\left[\begin{array}{cccccccc}
y(0) & y(-1) & \mathrm{L} & y\left(1-a_{n}\right) & x(0) & x(-1) & \mathrm{L} & x\left(1-b_{n}\right) \\
y(1) & y(0) & \mathrm{L} & y\left(2-a_{n}\right) & x(1) & x(0) & \mathrm{L} & x\left(2-b_{n}\right) \\
\mathrm{M} & \mathrm{M} & & \mathrm{M} & \mathrm{M} & \mathrm{M} & & \mathrm{M} \\
y(m-1) & y(m-2) & \mathrm{L} & y\left(m-a_{n}\right) & x(m-1) & x(m-2) & \mathrm{L} & x\left(m-b_{n}\right)
\end{array}\right]
\end{aligned}
$$

)

In the system identification by PSO algorithm, each particle is the system parameter to be identified. According to the results of identification, the square of the difference value between predicated output and actual output can be calculated and considered as fitness value, and the identification of system parameters can be judged and optimized. In order to verify the system identification ability of PSO algorithm, through the simulation of the known system model, according to its simulation input and output signal, standard PSO, QPSO and PFQPSO algorithms are adopted respectively for system identification.

The simulation object is shown in Equation (5),

$$
H(z)=\frac{b_{0}+b_{1} z^{-1}+b_{2} z^{-2}}{a_{0}+a_{1} z^{-1}+a_{2} z^{-2}}
$$

The population size of standard PSO, QPSO and PFQPSO algorithms is 50 , and the maximum number of iterations is 500 .

The setting of standard PSO algorithm is presented. The inertia weight $\omega$ is decreased linearly from 0.9 to $0.4, c_{1}$ and $c_{2}$ are set to be 2 , and the value range of particle is $a_{i}, b_{i} \in[-2$,

\begin{tabular}{|c|c|c|c|c|c|c|c|}
\hline \multirow{2}{*}{ algorithms } & \multicolumn{6}{|c|}{ optimal parameters } & \multirow{2}{*}{$\begin{array}{l}\text { fitness } \\
\text { value }\end{array}$} \\
\hline & b0 & b1 & b2 & $\mathrm{a} 0$ & a1 & a2 & \\
\hline
\end{tabular}
2].

The setting of QPSO algorithm is given. a is linearly decreased from 1 to 0.5 , and the value range of particle is $a_{i}, b_{i} \in[-2,2]$.

The setting of improved QPSO algorithm is provided. a is linearly decreased from 1 to 0.5 , $\lambda=0.1$, and the value range of particle is $a_{i}, b_{i} \in\left[\begin{array}{ll}-2, & 2\end{array}\right]$.

Table 1 The simulation results of different algorithms 


\begin{tabular}{|l|l|l|l|l|l|l|l|}
\hline PSO & 0.001532 & 0.003081 & 0.001531 & 1.000000 & -1.91705 & 0.923195 & $1.255 \mathrm{E}-10$ \\
\hline QPSO & 0.001538 & 0.003068 & 0.001538 & 1.000000 & -1.91705 & 0.923195 & $6.135 \mathrm{E}-11$ \\
\hline PFQPSO & 0.001537 & 0.003071 & 0.001537 & 1.000000 & -1.91705 & 0.923195 & $2.306 \mathrm{E}-20$ \\
\hline
\end{tabular}

Different algorithms are executed for 50 times, and the minimum error is selected. The simulation results are shown in Table 1 . Table 1 shows the simulation results of different algorithms. It can be seen that the error of system identification by QPSO algorithm is far less than that by standard PSO algorithm. Whereas, the error of PFQPSO algorithm is far less than that of QPSO algorithm, and its results is nearly close to truth value.

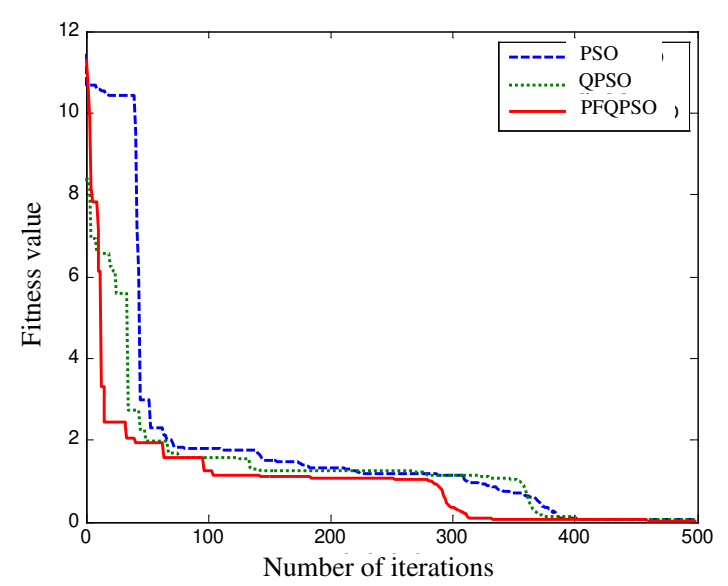

Figure 1 The comparison of convergence curve of standard PSO, QPSO and PFQPSO algorithms
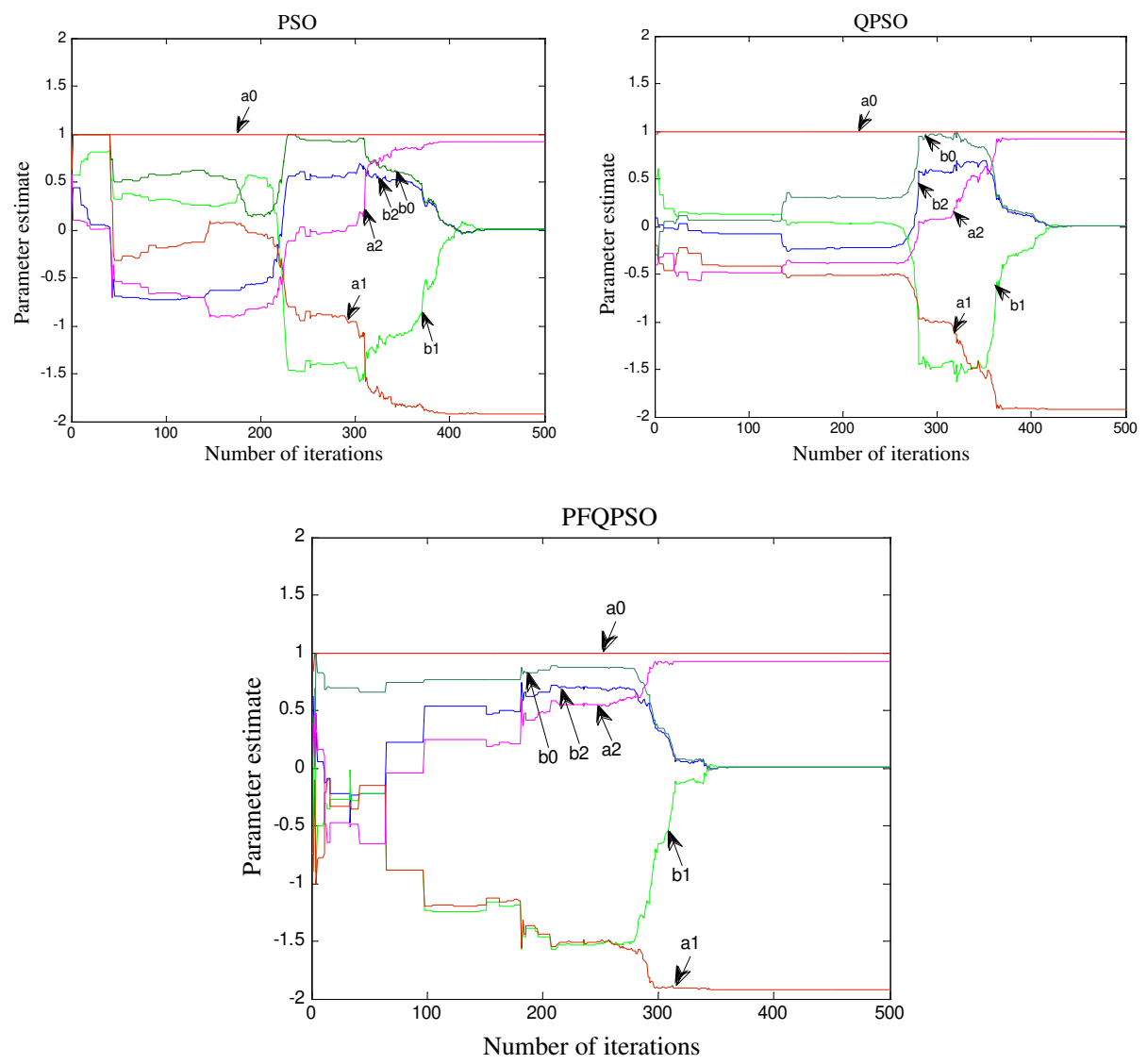

Figure 2 The comparison of parameter estimation of standard PSO, QPSO and PFQPSO algorithms 
Figure 1 and Figure 2 show the fitness value of 500 iterations of system identification by standard PSO, QPSO and PFQPSO algorithms and the change trajectory of parameters, respectively. It can be seen that the convergence speeds of standard PSO, QPSO and PFQPSO algorithms is increasing successively. PFQPSO can reach the convergence after 310 times of iterations, and the average error of PFQPSO on training set is far less than that of the other two algorithms. It can be concluded from the optimal parameters obtained from simulation that, the accuracy of parameters from PFQPSO is the best, which nearly approximates to truth value when noise exists. Therefore, the simulation experiment shows that PFQPSO has a more rapid convergence speed and higher accuracy in system identification.

\section{Experiments}

The essence of this method is to convert the design of the dynamic compensator to the identification of the compensator parameters by experiments. The principle of sensor dynamic error correction based on the PFQPSO algorithm is to reversely identify the sensor calibration data by using an intelligent optimization algorithm, and use the acquired sensor inverse model as the sensor dynamic compensator ${ }^{[10]}$. Its basic principle is shown in Figure 3 .

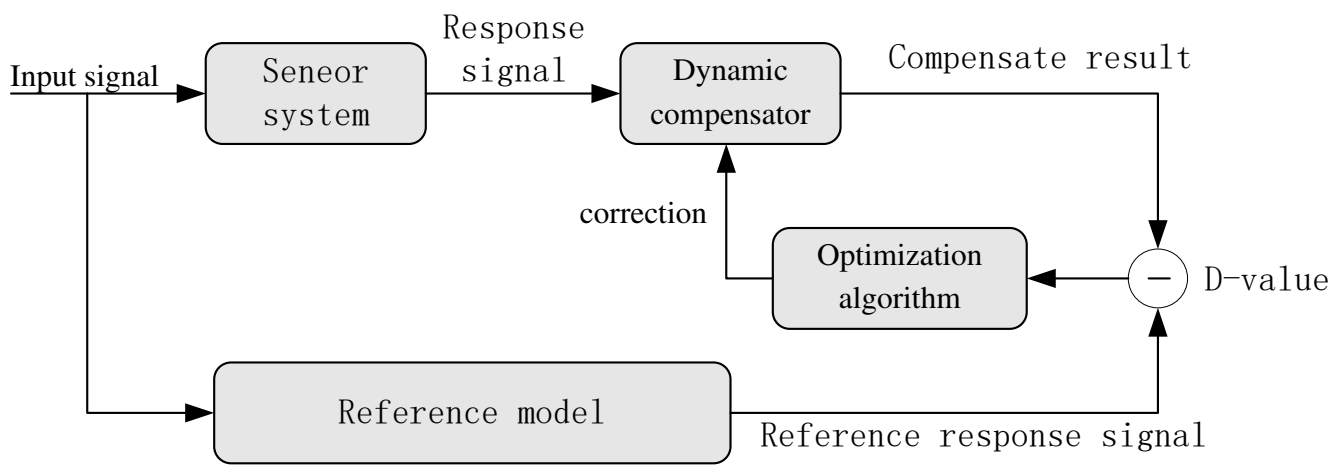

Figure 3 The basic functional block diagram of inverse modeling

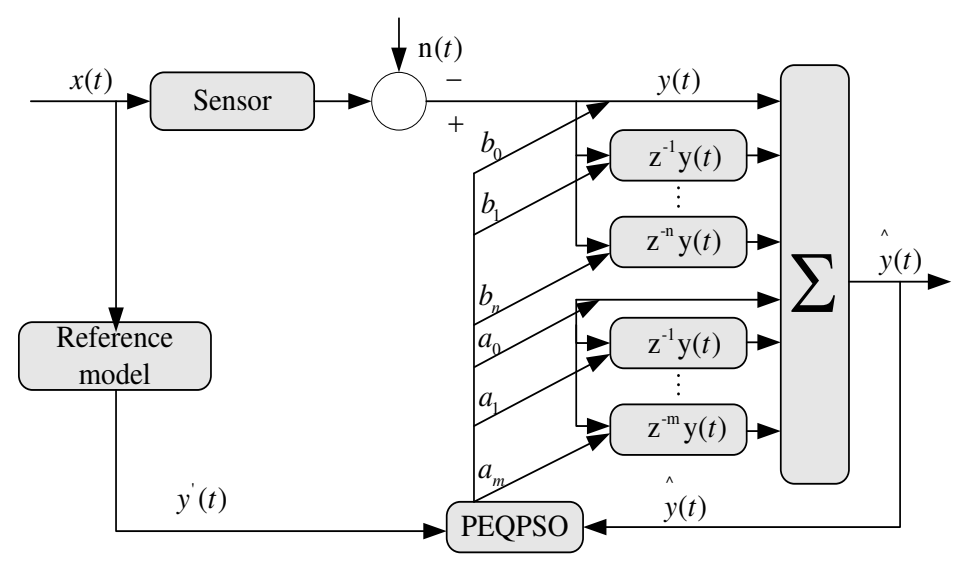

Figure 4 The design schematic diagram of sensor dynamic compensation filter based on PFQPSO

Figure 4 shows the general principle of sensor dynamic error correction based on PFQPSO,

in which, $\mathrm{y}(\mathrm{t})$ is sensor output signal, $\mathrm{y}^{\prime}(\mathrm{t})$ is the reference model output signal, $\hat{\mathrm{y}}(\mathrm{t})$ is the compensated output signal, and $m$ is the highest order of dynamic compensator. First of all, the dynamic calibration experiment is conducted on sensor to obtain its response to step 
signal. Then the output signal of sensor is taken as the input signal of compensator, and the step signal is taken as the output signal of compensator. Next, the inverse identification is performed on the parameters of compensation filter by PFQPSO, so as to obtain the transfer function of compensation filter and realize the compensation and correction of sensor dynamic error.

The dynamic compensation filter model is determined by the minimum mean squared error and the overshoot value of compensated data relative to ideal step signal, by making use of the response data of pressure sensor under the excitation of step signal in the movable-scale experiment of shock tube ${ }^{[11]}$. Figure 5 and Figure 6 is the relationship between the compensator order of $8510 \mathrm{~B}$ sensor from American Endevco Company and error of mean square, as well as overshoot.

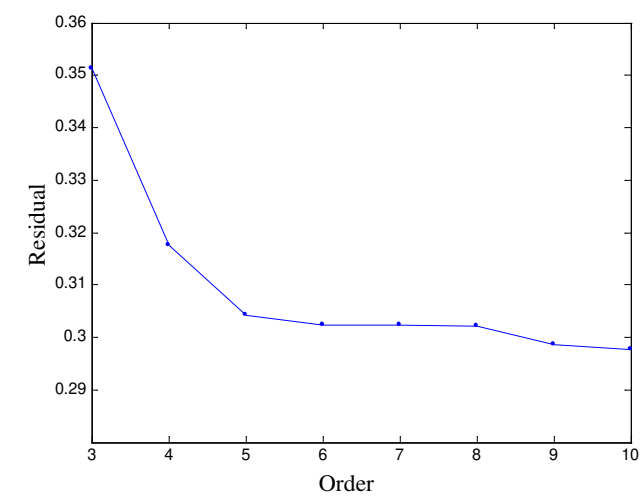

Figure 5 The relationship between the compensator order of 8510B sensor and error of mean square

$x=[3456789$ 10]; order

$y=\left[\begin{array}{lll}7.3 & 5.4 & 4.4 \\ 4.7 & 4.8 & 4.64 .84 .5\end{array}\right]$; overshoot

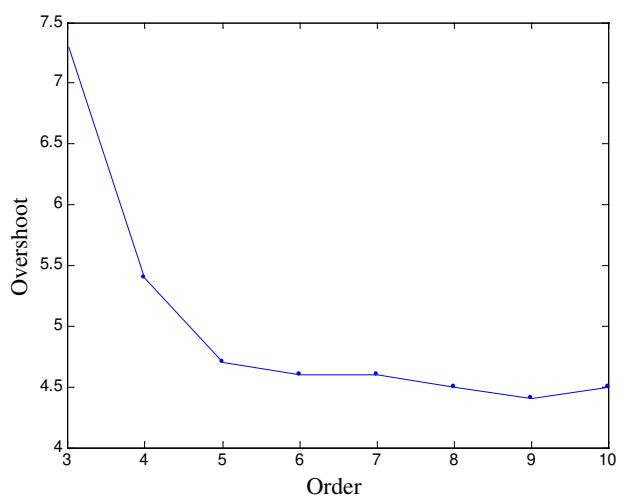

Figure 6 The relationship between the compensator order of $8510 \mathrm{~B}$ sensor

It can be seen from Fig. 5 to Fig. 6 that the mean square error and overshoot curve of the data after compensation gradually decrease with the increase of the order. The order of the compensation filter of this sensor decreases obviously after the 5th order. Due to some noise of system and sensor structure, a high-order system can be applied to describe more accurately the pressure sensor system, establish the compensator of corresponding order and obtain better compensation result of compensation from sensor output. However, the higher order of compensation filter, the harder the realization of its hardware, which is hard to be inserted in test system. After balancing the compensation effect and the difficulty to realize the hardware of filter, the order of 8510B compensation filter from American Endevco Company is selected to be 5 . 
With the improved QPSO, the dynamic compensation filter of sensor is built by inverse modeling, which has the advantages of simple algorithm and good convergence. This paper carries out the modeling of dynamic compensation filter on 8510B piezoresistive pressure sensor from American Endevco Company, and analyzes the indicators of its frequency domain and time domain performance to judge the compensation effect of dynamic compensation filter built by this algorithm. The indicator of frequency domain performance is mainly to analyze its effective bandwidth (the working band when the amplitude error is $\pm 3 \mathrm{~dB}$ ); the time domain performance is mainly to analyze its overshoot, rise time, peak time and steady-state response time $( \pm 5 \%)$.

The dynamic compensation filter model of $8510 \mathrm{~B}$ piezoresistive pressure sensor from Endevco Company is shown in Equation (7).

The coefficient values are given.

$$
\begin{array}{llllll}
b_{0}=-1.003970 & b_{1}=-0.124788 & b_{2}=-0.858342 & b_{3}=-0.140772 & b_{4}=-0.481996 & b_{5}=-0.085275 \\
a_{0}=-1.401758 & a_{1}=-0.588599 & a_{2}=0.234809 & a_{3}=-0.655360 & a_{4}=-0.581886 & a_{5}=-0.313028
\end{array}
$$

The model of equivalent system after compensation is shown in Equation (8).

The coefficient values are provided.

$$
\begin{aligned}
& d_{0}=1.415103 d_{1}=1.177521 d_{2}=0.040734 d_{3}=-0.970338 d_{4}=-0.539432 \\
& d_{5}=0.604072 d_{6}=1.123248 d_{7}=0.887328 d_{8}=0.125176 d_{9}=-0.652276 d_{10}=-0.409326 \\
& c_{0}=2.496802 c_{1}=0.869065 c_{2}=-0.377827 c_{3}=-1.986814 c_{4}=-0.525491 \\
& c_{5}=1.969847 c_{6}=1.423296 c_{7}=0.743668 c_{8}=-0.948631 c_{9}=-0.861911 c_{10}=0.007217
\end{aligned}
$$

\section{Results and Discussion}

The frequency of shock wave signal reaches up to $100 \mathrm{kHz}$, so the effective bandwidth of sensor shall be more than $100 \mathrm{kHz}( \pm 3 \mathrm{~dB})^{[12]}$. It can be seen from Figure 7 that, the main resonant frequency of original sensor system is $83 \mathrm{kHz}$; the effective bandwidth $( \pm 3 \mathrm{~dB})$ is $32 \mathrm{kHz}$; the working frequency is $9 \mathrm{kHz}$, when the amplitude error is $\pm 2 \%$; the working frequency is $12 \mathrm{kHz}$, when the amplitude error is $\pm 5 \%$; the working frequency is $17 \mathrm{kHz}$, when the amplitude error is $\pm 10 \%$. However, the effective bandwidth $( \pm 3 \mathrm{~dB})$ of system after the compensation of compensation filter is $149 \mathrm{kHz}$; the working frequency is $14 \mathrm{kHz}$, when the amplitude error is $\pm 2 \%$; the working frequency is $25 \mathrm{kHz}$, when the amplitude error is $\pm 5 \%$; the working frequency is $42 \mathrm{kHz}$, when the amplitude error is $\pm 10 \%$. 


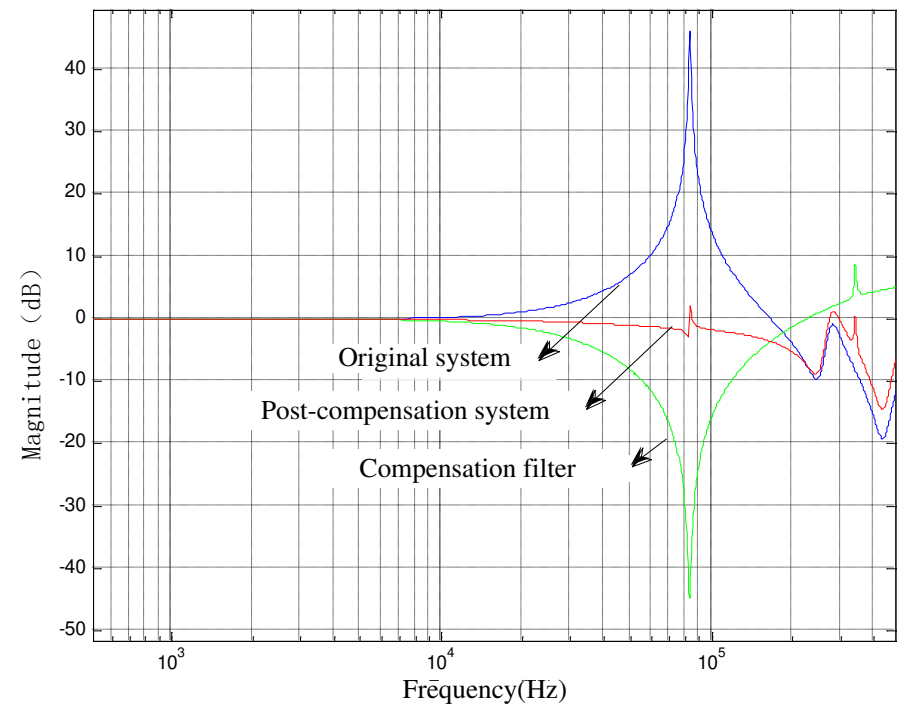

Figure 7 The amplitude-frequency characteristic of sensor before and after compensation by PFQPSO for $8510 B$ sensor

The verification of time domain performance

In order to analyze the time domain performance of sensor system before and after the compensation, the built dynamic compensation filter can be applied to obtain the step response of sensor system after compensation ${ }^{[13]}$, and to compare various performance indicators of time domain.

The step response output of $8510 \mathrm{~B}$ piezoresistive pressure sensor from Endevco Company before and after compensation by PFQPSO is shown in Figure 8.

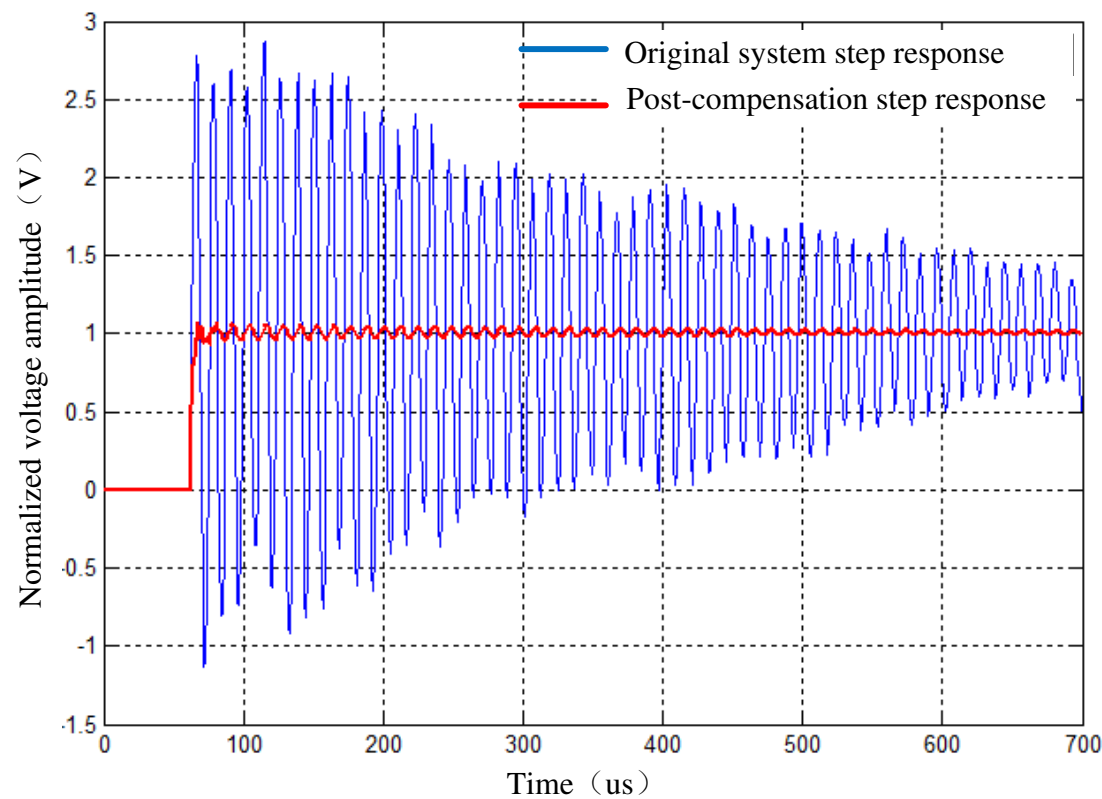

Figure 8 The comparison of step response output of 8510B piezoresistive pressure sensor before and after compensation by PFQPSO

Table 2 The comparison of time domain performance of 8510B piezoresistive pressure sensor from Endevco Company before and after compensation 


\begin{tabular}{|l|l|l|}
\hline $\begin{array}{l}\text { Time-domain } \\
\text { performance } \\
\text { indicators }\end{array}$ & $\begin{array}{l}\text { Before } \\
\text { compensation }\end{array}$ & $\begin{array}{l}\text { After } \\
\text { compensation }\end{array}$ \\
\hline Overshoot & $110.8 \%$ & $4.4 \%$ \\
\hline Time of rise & $4.1 \mu \mathrm{s}$ & $3.8 \mu \mathrm{s}$ \\
\hline Peak time & $9.1 \mu \mathrm{s}$ & $5.8 \mu \mathrm{s}$ \\
\hline $\begin{array}{l}\text { Steady-state response } \\
\text { time } \pm 5 \%)\end{array}$ & $1.5 \mathrm{~ms}$ & $7 \mu \mathrm{s}$ \\
\hline
\end{tabular}

In order to explain the repeatability of compensator with the optimal order for the same sensor, the compensator with the optimal order is adopted for 10 times of shock tube data rated by one sensor, to examine the consistency of compensation characteristic of time domain and frequency domain. The result of time domain indicator is shown in Table 2, and the result of frequency indicator is shown in Table 3.

Table 3 The overshoot data of ten times of repetitive experiments of $8510 \mathrm{~B}$ sensor from Endevco Company (normalization)

\begin{tabular}{|l|l|l|l|l|l|}
\hline $\begin{array}{l}\text { Optimal } \\
\text { order }\end{array}$ & $\begin{array}{l}\text { Experimental } \\
\text { serial number }\end{array}$ & $\begin{array}{l}\text { Original } \\
\text { overpressure } \\
\text { peak }\end{array}$ & $\begin{array}{l}\text { Original } \\
\text { overshoot\% }\end{array}$ & $\begin{array}{l}\text { Post-compensation } \\
\text { peak }\end{array}$ & $\begin{array}{l}\text { Overshoot after } \\
\text { compensation\% }\end{array}$ \\
\hline \multirow{5}{*}{$n=5$} & 2.724 & 172.4 & 1.039 & 3.9 \\
\cline { 2 - 6 } & 1 & 2.592 & 159.2 & 1.041 & 4.1 \\
\cline { 2 - 6 } & 3 & 2.193 & 119.3 & 1.032 & 3.2 \\
\hline & 4 & 2.266 & 126.6 & 1.029 & 2.9 \\
\hline & 5 & 2.852 & 185.2 & 1.033 & 3.3 \\
\hline & 7 & 2.372 & 137.2 & 1.046 & 4.6 \\
\hline & 8 & 2.434 & 143.4 & 1.028 & 2.8 \\
\hline & 9 & 2.794 & 179.4 & 1.031 & 3.1 \\
\hline 10 & 2.705 & 170.5 & 1.043 & 4.3 \\
\hline
\end{tabular}

From the data, it can be concluded that, there is a large difference between different sensors for original overshoot, which is caused by the larger difference in the characteristics of sensor (mainly inherent frequency).

Whereas, the original overshoot of ten times of shock wave data of $8510 \mathrm{~B}$ from Endevco Company is averaged to $154.9 \%$, with the highest value of $185.2 \%$. The mean value of overshoot after compensation is $3.58 \%$.

Table 4 The frequency domain indicator of ten times of repetitive experiments of $8510 \mathrm{~B}$ sensor from Endevco Company

\begin{tabular}{|l|l|l|l|l|l|}
\hline $\begin{array}{l}\text { Optimal } \\
\text { order }\end{array}$ & $\begin{array}{l}\text { Effective } \\
\text { bandwidth }\end{array}$ & $\begin{array}{l}\text { Effective } \\
\text { bandwidth }\end{array}$ & $\begin{array}{l}\text { Amplitude } \\
\text { error } \pm 2 \%(\mathrm{kHz})\end{array}$ & $\begin{array}{l}\text { Amplitude } \\
\text { error } \pm 5 \%(\mathrm{kHz})\end{array}$ & $\begin{array}{l}\text { Amplitude } \\
\text { error } \pm 10 \%(\mathrm{kHz})\end{array}$ \\
\hline
\end{tabular}




\begin{tabular}{|l|l|l|l|l|l|l|l|l|}
\hline & $\begin{array}{l}\text { before } \\
\text { compensatio } \\
\mathrm{n}(\mathrm{kHz})\end{array}$ & $\begin{array}{l}\text { after } \\
\text { compensatio } \\
\mathrm{n}(\mathrm{kHz})\end{array}$ & $\begin{array}{l}\text { Before } \\
\text { compens } \\
\text { ation }\end{array}$ & $\begin{array}{l}\text { after } \\
\text { compens } \\
\text { ation }\end{array}$ & $\begin{array}{l}\text { Before } \\
\text { compens } \\
\text { ation }\end{array}$ & $\begin{array}{l}\text { after } \\
\text { compens } \\
\text { ation }\end{array}$ & $\begin{array}{l}\text { Before } \\
\text { compensat } \\
\text { ion }\end{array}$ & $\begin{array}{l}\text { after } \\
\text { ampens } \\
\text { ation }\end{array}$ \\
\hline 32.2 & 149.6 & 9.4 & 14.7 & 12.6 & 25.7 & 17.1 & 42.2 \\
\hline 31.4 & 148.3 & 9.2 & 15.3 & 12.7 & 24.9 & 16.9 & 43.1 \\
\hline \multirow{5}{*}{$\mathrm{n}=5$} & 147.9 & 8.7 & 14.4 & 11.9 & 25.3 & 16.4 & 42.6 \\
\hline & 33.4 & 148.6 & 10.4 & 15.1 & 11.6 & 26.7 & 17.3 & 43.6 \\
\hline 32.7 & 149.6 & 9.4 & 15.4 & 12.7 & 26.4 & 17.2 & 42.7 \\
\hline & 31.9 & 147.8 & 10.7 & 14.5 & 13.1 & 25.1 & 17.9 & 43.8 \\
\hline 34.1 & 147.9 & 9.1 & 14.8 & 12.3 & 26.8 & 16.4 & 43.7 \\
\hline 33.1 & 146.9 & 9.7 & 15.3 & 13.1 & 26.7 & 16.5 & 42.9 \\
\hline 32.7 & 148.3 & 9.4 & 14.4 & 12.7 & 25.9 & 16.7 & 44.1 \\
\hline & 34.1 & 146.5 & 10.1 & 14.0 & 12.9 & 26.1 & 14.9 & 43.8 \\
\hline
\end{tabular}

It can be seen from Table 4 that the frequency domain indicator of ten times of repetitive shock tube experiments for the same one sensor is consistent. There is a good repeatability in the compensation effect of the compensator with the optimal order for the same one sensor. At the same time, the compensation effect of compensator obtained by PFQPSO is further verified, suitable for practical overpressure measurement of shock wave.

\section{Conclusion}

This paper proposes and studies the design method of pressure sensor dynamic compensation filter based on PFQPSO algorithm. Taking a sensor with poorer dynamic performance in 8510 series of sensor from Endevco Company as an example, this paper carries out the dynamic performance experiment of shock tube, modelling and the design, analysis and verification of dynamic compensation filter based on PFQPSO. The findings show that this method is feasible and effective. In addition, the dynamic compensation filter or inverse filter is recursive, which can be realized by IIR filter, suitable for real-time processing.

\section{List of Abbreviations}

QPSO: the quantum-behaved particle swarm optimization PSO: the particle swarm optimization

PFQPSO: the progressive function quantum-behaved particle swarm optimization

\section{Declarations}

Ethical Approval and Consent to participate: Approved.

Consent for publication: Approved.

Availability of supporting data: We can provide the data.

\section{Competing interests}

These no potential competing interests in our paper. And all authors have seen the manuscript and approved to submit to your journal. We confirm that the content of the manuscript has not been published or submitted for publication elsewhere.

\section{Funding}


This work was supported by the National Natural Science Foundation of China (Approved Nos. 51575499 and 61473267) and the Natural Science Foundation of Shanxi Province of China (Approved Nos. 201801D121161) and Sponsored by the Fund for Shanxi '1331 K SC'.

\section{Author's contributions}

The author takes part in the discussion of the work described in this paper. The author contributed to this work and should be considered the first author.

\section{Acknowledgements}

The author thank the editor and anonymous reviewers for their helpful comments and valuable suggestions. I would like to acknowledge all our team members.

\section{Author details}

Wei Wang :3 Xueyuan Road, School of Instrument and Electronics Science and Technology, the North University of China,Taiyuan, Shanxi, P.R.China.

\section{References}

[1] Zhi-Jie Zhang, Wei Wang. Measurement Theories and Practical Developments Correction of Dynamic Error Result from Measurement System Limitations[J].Journal of Measurement Science and Instrumentation.2010,1(4) : 307-312

[2] Fan BS, Tan GZ, Fan SS. Comparison of Three Different 2-D Space Vector PWM Algorithms and Their FPGA Implementations. Journal of Power Technologies. 2014; 94(3): 176-189. [3] Grimaidi. Domenico, "Distributed measurement system," Measurement Journal of The International, vol. 30,no.7, pp.279-287,2001.

[3] Luo X, Liu D, and Ye D, "Multi-agent based distributed measurement systems in CORBA environment," IEEE Instrumentation and Measurement Technology Conference, vol.2,no.8, pp.821-826,2001.

[4] Xianfeng ZHENG and Zheng FAN, "Design of the zigbee technology-based wireless sensor network for earth temperature monitoring," International Journal of Online Engineering, vol.10, no.5, pp. 63-67, 2014. http://dx.doi.org/10.3991/ ijoe.v10i5.4034

[5] Zhong YQ, Zhao L. Design and implementation of receiver front-end filter in wireless sensor networks. Chinese Journal of Sensors and actuators. 2009; 22(7): 1034-1039. [7] De La Rosa and Juan José González, "A web-based distributed measurement system for electrical power qualityassessment,"Journal of the International Measurement Confederation,vol. 6,no.3, pp.771-780,2010.

[6] Kirabyaz S, Pulkkinen J, Gabbouj M. Multi-Dimensional Particle Swarm Optimization in Dynamic Environments[J]. Expert Systems with Applications, 2011, 38(3) : 2112-2223.

[7] Kennedy J. Probability and Dynamics in the Particle Swarm[C]. In : Proc. of IEEE Congress on Evolutionary Computation. Piscataway, NJ : IEEE Conference Publications, 2004. 340-347.

[8] Ciancetta, Fabrizio, Bucci, and Giovanni, D'Apice Biagio, "A distributed measurement system based on Peer-To-Peer architecture for River Monitoring,"Virtual Environments Human-Computer Interfaces and Measurement Systems,vol.4,no.4, pp.87-92,2007.

[9] Rappaport T. S, “Wireless communications: principles and practice," New York: Prentice Hall, vol.2,no.5, pp.152-156, 2001. 
[10] Salman M.K., Ahmad R.B., Yahya Abid, "A new approach for efficient utilization of resources in WiMAX cellular networks,"Tehnicki Vjesnik, vol.21, no.6, pp. 1385-1393, 2014.

[11] Salman M.K., Ahmad R.B., Yahya Abid, "A new approach for efficient utilization of resources in WiMAX cellular networks," Tehnicki Vjesnik, vol.21, no.6, pp. 1385-1393, 2014.

[12] Ciancetta Fabrizio, Fiorucci Edoardo, and Gallo Daniele, "A Web Service interface for a distributed measurement system based on decentralized sharing network," Sensors and Transducers, vol.6,no.10, pp.209-218,2013.

[13] Harikrishna D. Dynamic stability enhancement of power systems using neural-network controlled static-compensator. TELKOMNIKA (Telecommunication, Computing, Electronics and Control). 2013;10(1): 9-12. 


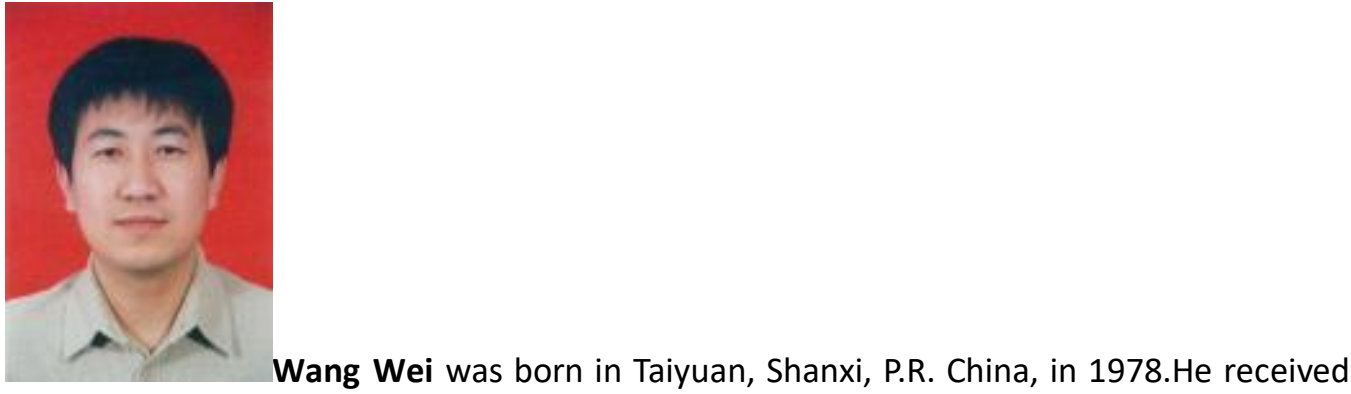
the Ph.D degree in Instrument and electronics from the North University of China, in 2016. Now, he works in School of Instrument and Electronics, North University of China. His scientific research interests are concerned with digital signal processing in dynamic measurement and uncertainty of measurement systems.

\section{Figures}

Figure 1 The comparison of convergence curve of standard PSO, QPSO and PFQPSO algorithms

Figure 2 The comparison of parameter estimation of standard PSO, QPSO and PFQPSO algorithms

Figure 3 The basic functional block diagram of inverse modeling

Figure 4 The design schematic diagram of sensor dynamic compensation filter based on PFQPSO

Figure 5 The relationship between the compensator order of $8510 \mathrm{~B}$ sensor and error of mean square

Figure 6 The relationship between the compensator order of $8510 \mathrm{~B}$ sensor

Figure 7 The amplitude-frequency characteristic of sensor before and after compensation by PFQPSO for $8510 \mathrm{~B}$ sensor

Figure 8 The comparison of step response output of $8510 \mathrm{~B}$ piezoresistive pressure sensor before and after compensation by PFQPSO 
Figures

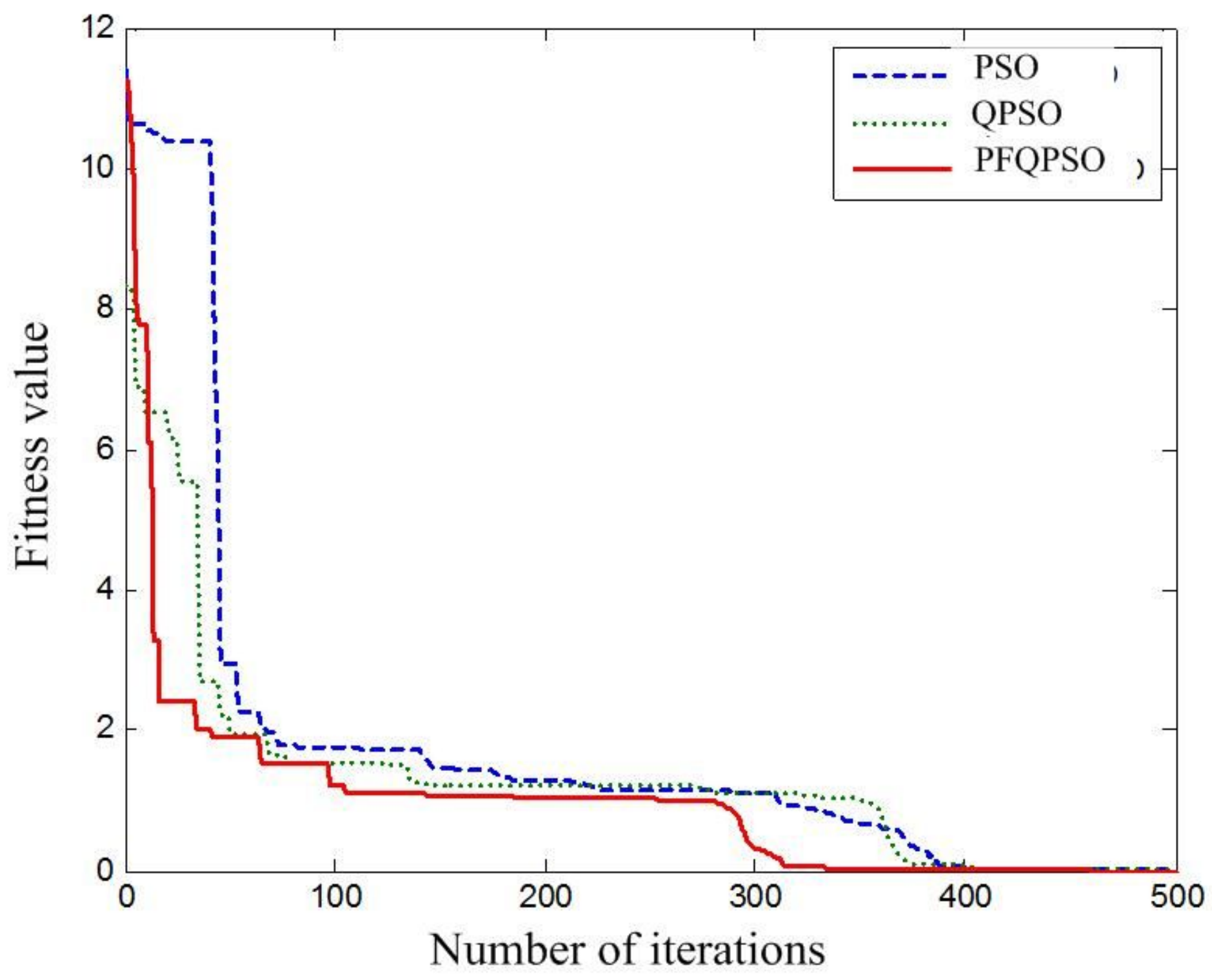

Figure 1

The comparison of convergence curve of standard PSO, QPSO and PFQPSO algorithms 

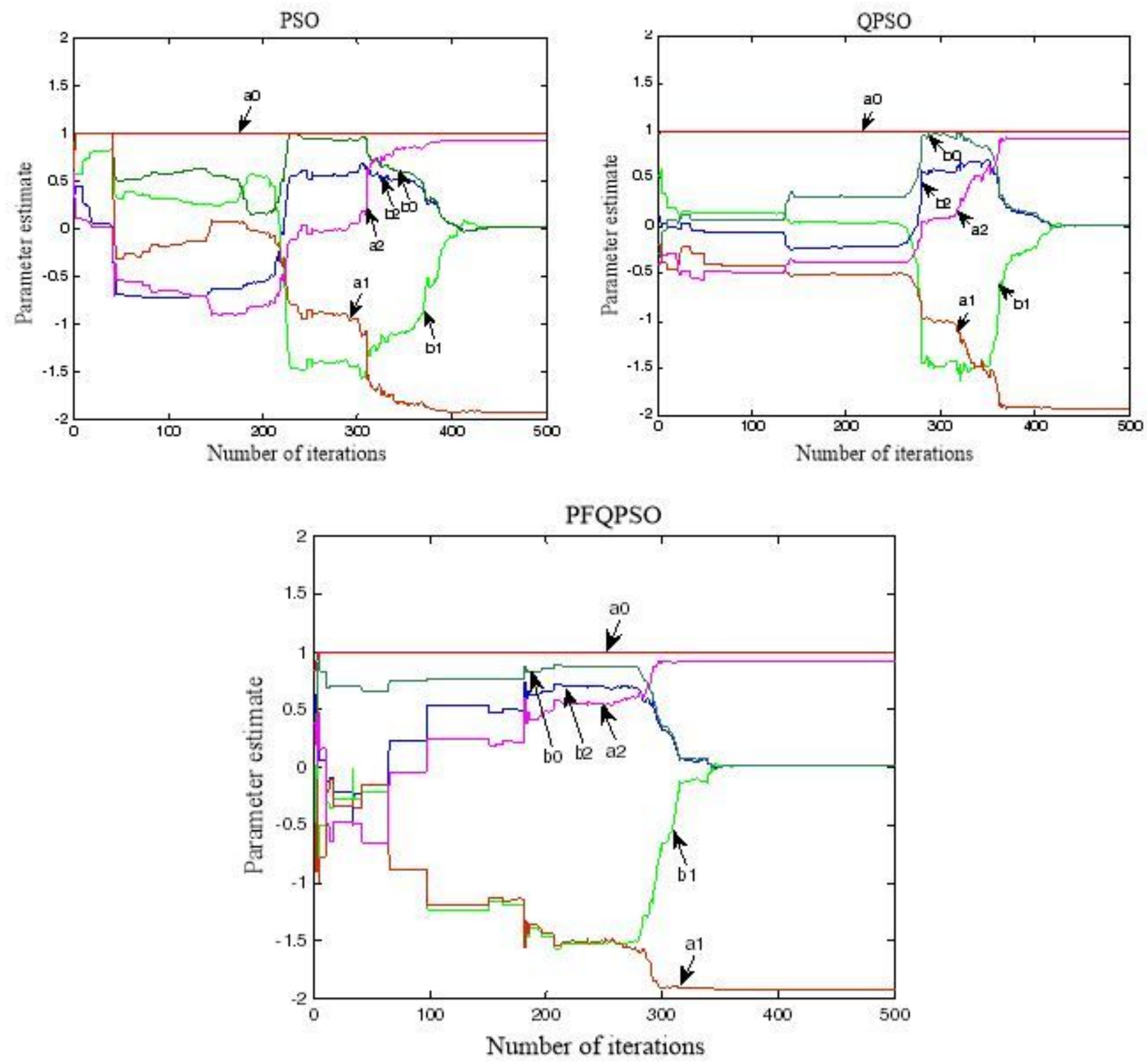

Figure 2

The comparison of parameter estimation of standard PSO, QPSO and PFQPSO algorithms 


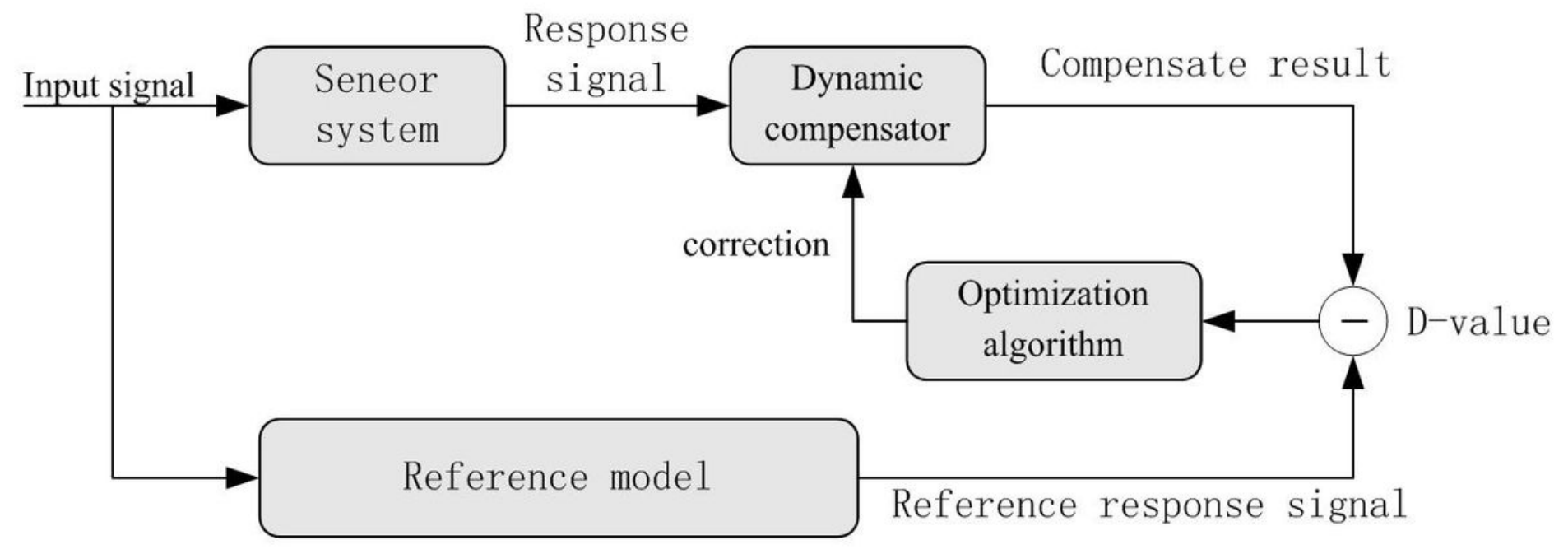

Figure 3

The basic functional block diagram of inverse modeling

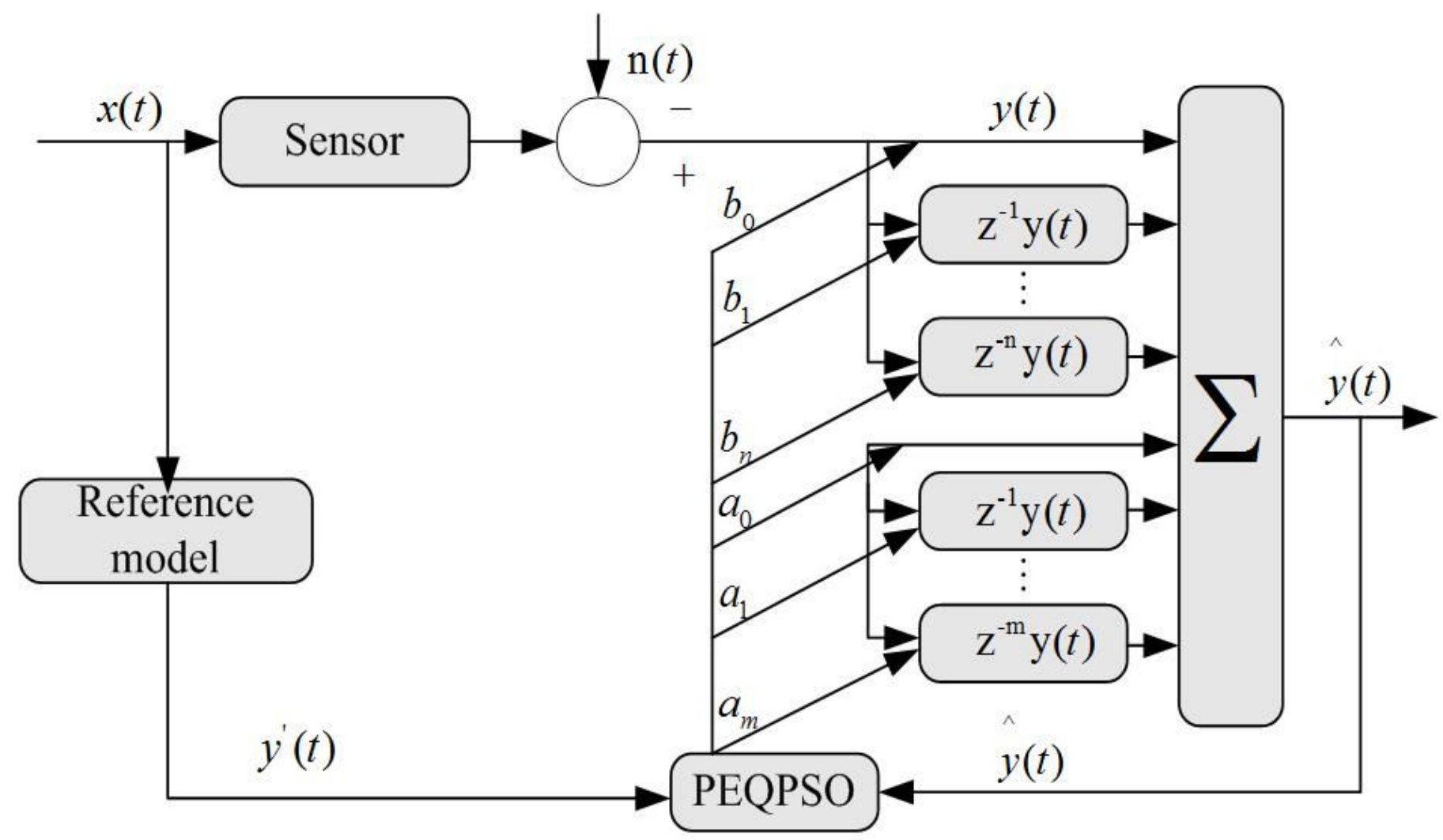

Figure 4

The design schematic diagram of sensor dynamic compensation filter based on PFQPSO 


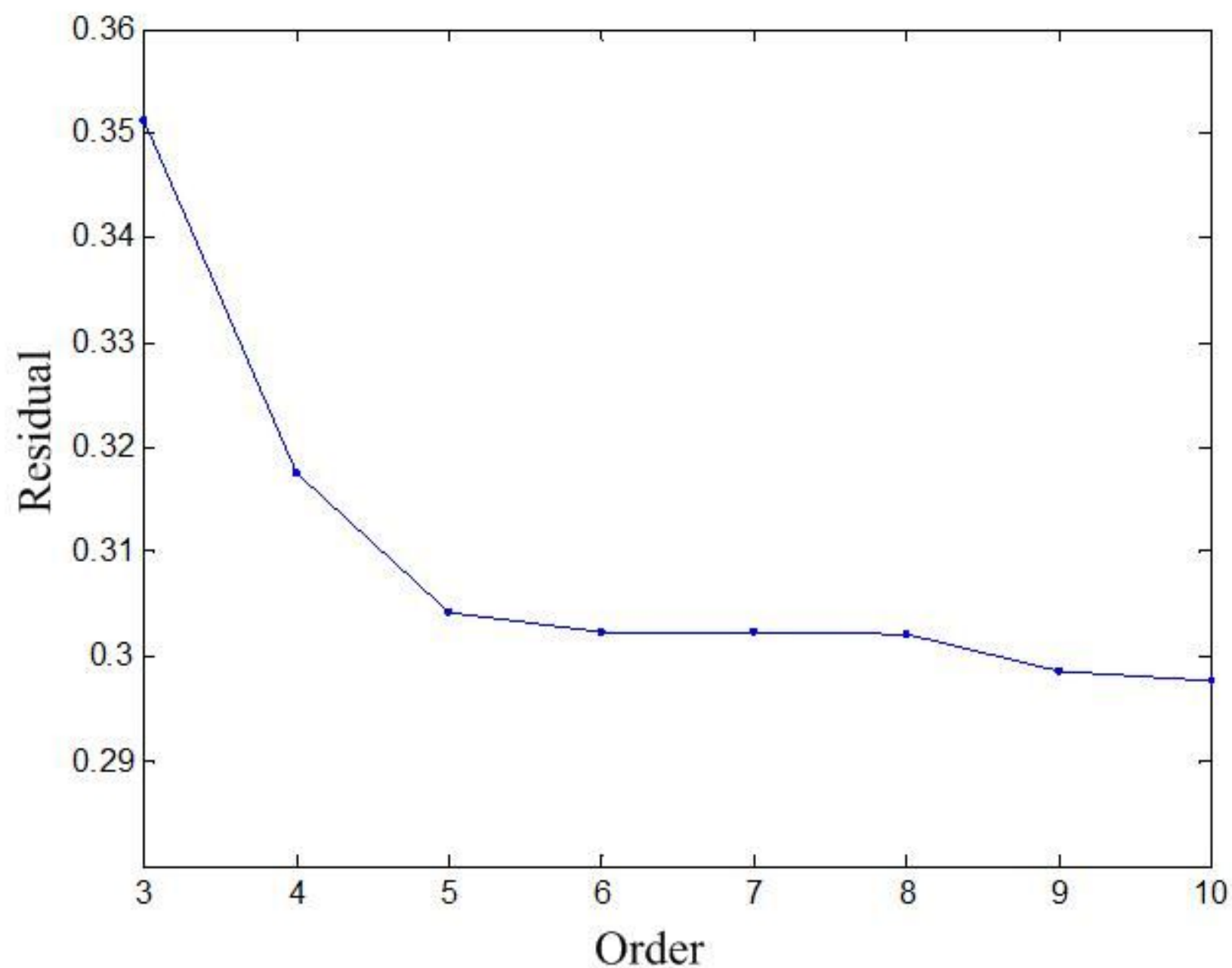

Figure 5

The relationship between the compensator order of 8510B sensor and error of mean square 


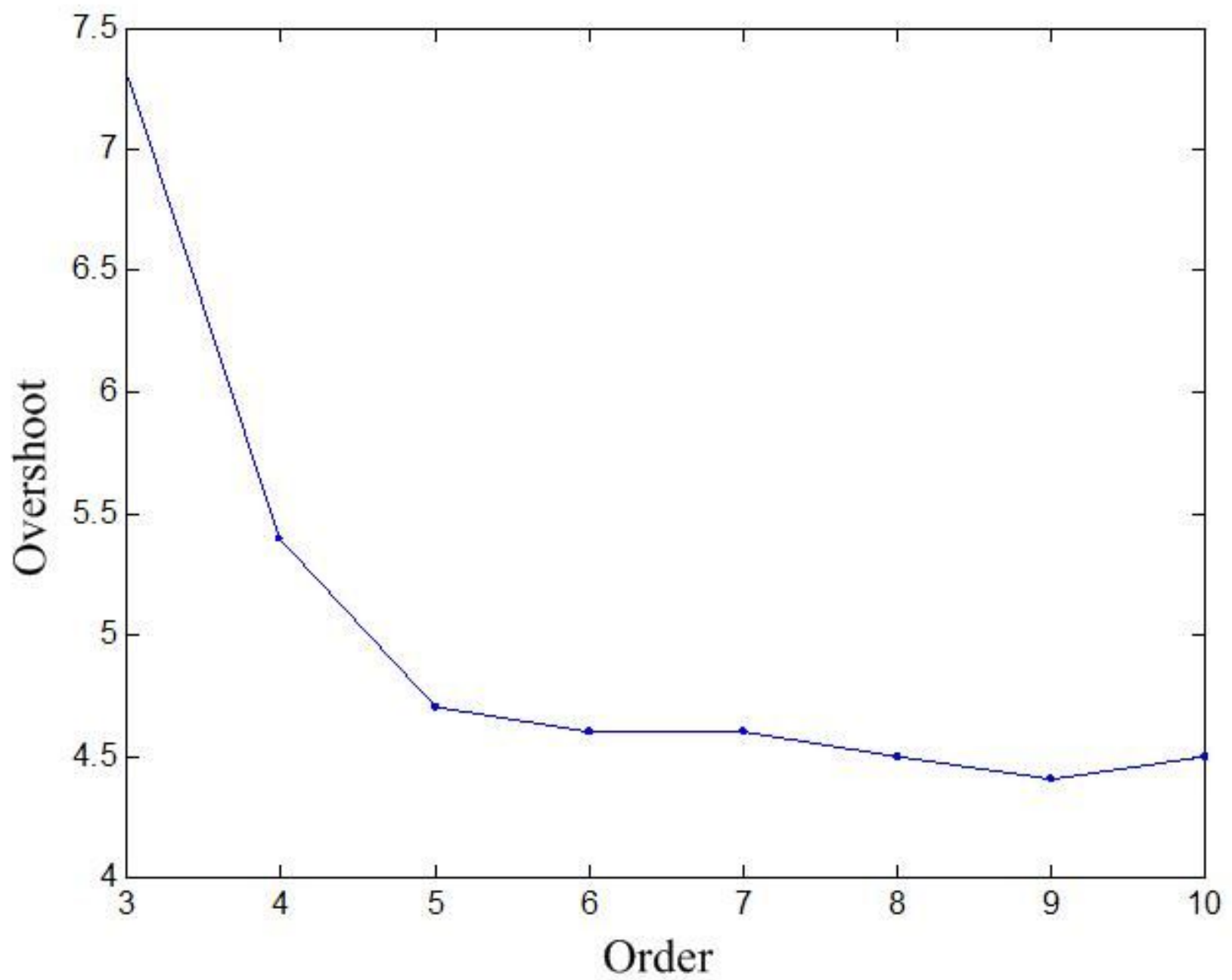

Figure 6

The relationship between the compensator order of 8510B sensor 


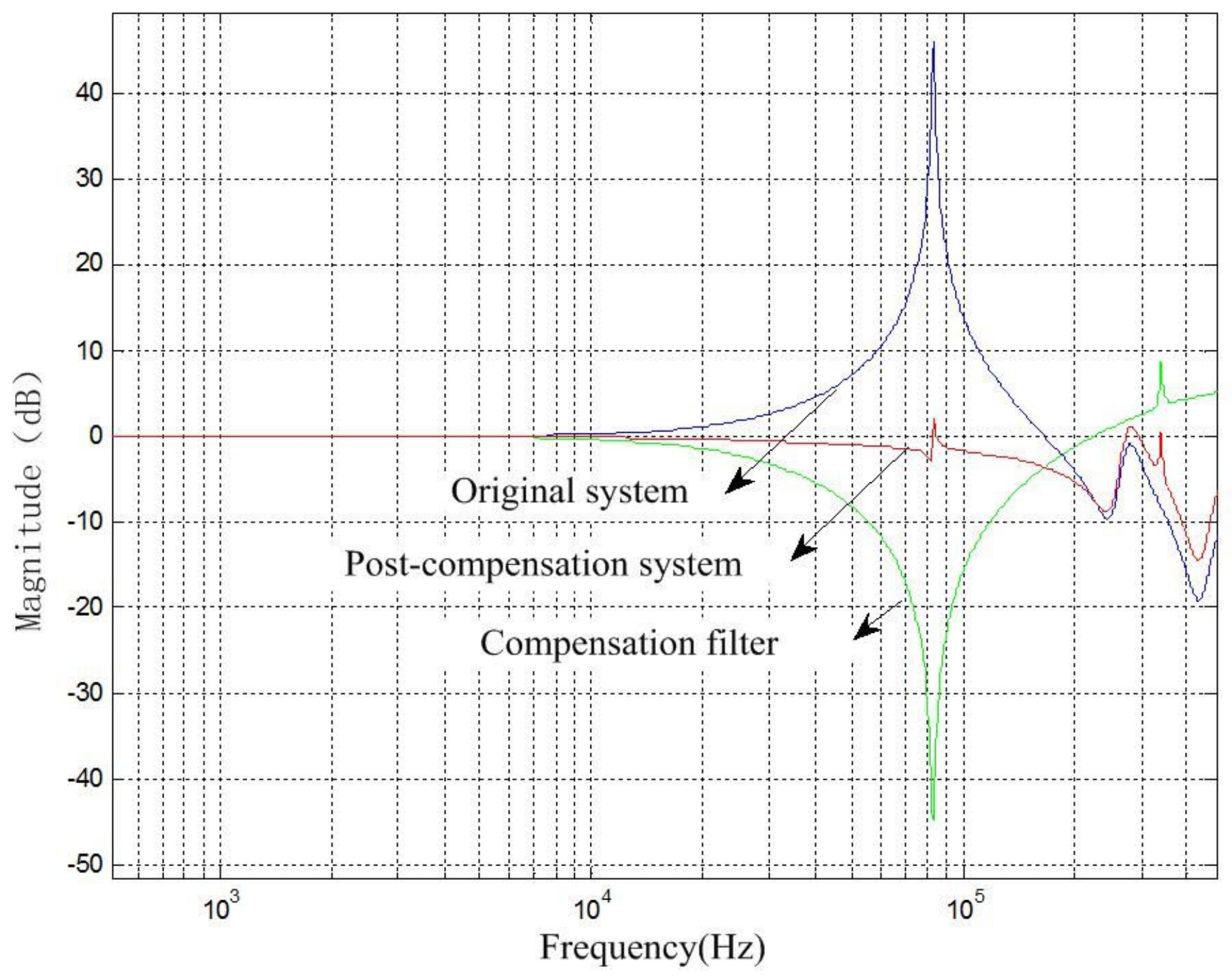

Figure 7

The amplitude-frequency characteristic of sensor before and after compensation by PFQPSO for $8510 \mathrm{~B}$ sensor 


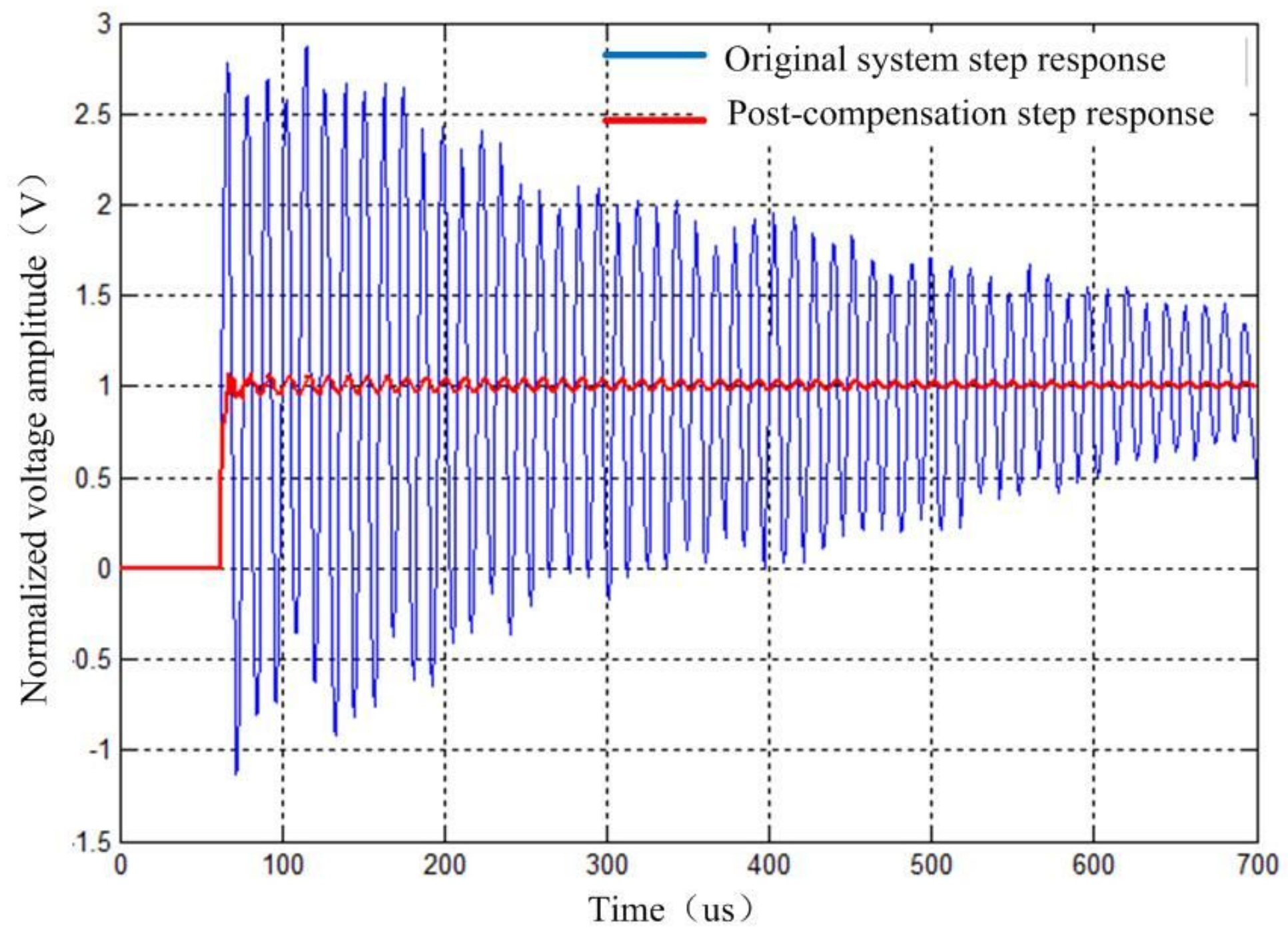

Figure 8

The comparison of step response output of 8510B piezoresistive pressure sensor before and after compensation by PFQPSO 